KIST. Eduardo Lamour. BAGATINI, Júlia. Responsabilidade civil: uma análise acerca das redes sociais. Revista Eletrônica Direito e Política, Programa de Pós-Graduação Stricto Sensu em Ciência Jurídica da UNIVALI, Itajaí, v.11, n.2, º quadrimestre de 2016. Disponível em: www.univali.br/direitoepolitica - ISSN 1980-7791.

\title{
RESPONSABILIDADE CIVIL: UMA ANÁLISE ACERCA DAS REDES SOCIAIS ${ }^{1}$
}

\author{
CIVIL LIABILITY: AN ANALYSIS ABOUT THE SOCIAL NETWORKS
}

\section{Eduardo Lamour Kist ${ }^{2}$ \\ Júlia Bagatini 3}

SUMÁRIO: Introdução: 1. Direitos da personalidade; 2. A responsabilidade civil por danos advindos do mau uso das redes sociais; 3. A responsabilidade civil de terceiros nas redes sociais, pelo compartilhamento de informações, comentários e curtidas realizadas; Considerações finais; Referências das fontes citadas

\section{RESUMO}

O objetivo do presente artigo é realizar um estudo sobre a responsabilidade civil nas redes sociais, com a finalidade de ponderar sobre as formas inadequadas de utilização dos atuais meios de comunicação virtual, suas consequências e como o presente instituto pode atuar na reparação dos danos causados pelos precursores da informação e terceiros. Assim, é certa e possível tal reparação pelos usuários considerados como terceiros - isto é, que não são considerados precursores da informação, mas realizam compartilhamentos, comentários ou curtidas referentes ao conteúdo inicial - sendo que também devem ser responsabilizados civilmente pelos atos danosos que cometem dentro desses meios de comunicação, conforme entendimento doutrinário e jurisprudencial. O método de abordagem é o dedutivo, partindo de uma premissa genérica e outra específica, chegando ao resultado necessário, enquanto os métodos de procedimento seriam o histórico, perfazendo a evolução histórica da temática, e o analítico, representando as análises realizadas no decorrer do trabalho.

${ }^{1} \mathrm{O}$ presente artigo advém de pesquisa realizada no trabalho de conclusão de curso do acadêmico Eduardo Lamour Kist, sob orientação da professora Júlia Bagatini.

2 Acadêmico do $10^{\circ}$ Semestre do Curso de Graduação em Direito pela FAI Faculdades. Itapiranga/SC - Brasil. E-mail: eduardokist@gmail.com.

3 Mestre em Direito pela UNISC. Especialista em Direito Administrativo pela FGF. Advogada. Professora da FAI Faculdades. Itapiranga/SC - Brasil. E-mail: juliabagatini@bol.com.br. 
KIST. Eduardo Lamour. BAGATINI, Júlia. Responsabilidade civil: uma análise acerca das redes sociais. Revista Eletrônica Direito e Política, Programa de Pós-Graduação Stricto Sensu em Ciência Jurídica da UNIVALI, Itajaí, v.11, n.2, º quadrimestre de 2016. Disponível em: www.univali.br/direitoepolitica - ISSN 1980-7791.

PALAVRAS-CHAVE: Redes Sociais. Responsabilidade Civil. Terceiros.

ABSTRACT: The purpose of this article is to conduct a study about civil liability in social networks, in order to ponder the inappropriate ways of using today's virtual communication media, its consequences and how the present institute can work to repair the damage caused by the precursors of information and third persons. Thus, it's certain and possible such repair by the users considered as third persons - that is, who are not considered precursors of information, but hold shares, comments or likes about the initial content - and that should also be civilly liable for the harmful acts committed within these communication media, according to doctrinal and jurisprudential understanding. The method of approach is deductive, starting from a general premise and other specific, reaching the required result, while the methods of procedure would be historical, making the historical development of the subject, and the analytical, representing the analysis performed in this work.

KEY-WORDS: Social Networks. Civil Liability. Third Persons.

\section{INTRODUÇÃO}

A responsabilidade civil, mesmo nos dias atuais, envolvendo os meios mais avançados de interatividade, possui extrema importância, tornando necessária uma análise mais aprofundada do referido instituto em comparação às novas formas de relacionamento, principalmente as redes sociais, perfazendo um dos meios mais utilizados atualmente.

Assim, é imprescindível partir da premissa em que os direitos da personalidade devem sempre ser observados nesses espaços, determinando seu conceito, suas características e classificações, até chegar ao campo da responsabilidade civil, analisando sua efetiva atuação nos danos advindos do mau uso das redes sociais, bem como nos casos de compartilhamento de informações, comentários e curtidas realizadas. 
KIST. Eduardo Lamour. BAGATINI, Júlia. Responsabilidade civil: uma análise acerca das redes sociais. Revista Eletrônica Direito e Política, Programa de Pós-Graduação Stricto Sensu em Ciência Jurídica da UNIVALI, Itajaí, v.11, n.2, º quadrimestre de 2016. Disponível em: www.univali.br/direitoepolitica - ISSN 1980-7791.

Esses meios de comunicação contemporâneos caracterizam muito mais modificações positivas do que negativas, porém, para tal, devem ser empregados sempre com consciência e compromisso por parte dos usuários, evitando que os direitos inerentes à personalidade destes sejam violados, bem como bens jurídicos de outras pessoas.

Portanto, o surgimento desses novos meios de comunicação passa a atingir várias esferas e campos de conhecimento, como a economia, a ciência, e principalmente a cultura das pessoas, que começam a depender dos mesmos para a realização das suas tarefas, sendo que o uso inadequado das redes sociais, seja mediante uma postagem direta, ou por meio de compartilhamento, comentário ou curtida, certamente ocasionará um dano que, por meio da responsabilidade civil, deverá ser reparado.

\section{DIREITOS DA PERSONALIDADE}

A proteção da pessoa é uma característica marcante no direito contemporâneo, assim como a tutela dos direitos inerentes ao ofendido, como os da personalidade, que são tratados propriamente do artigo 11 ao 21 , no atual Código Civil, além do caput do artigo $5^{\circ}$ da Constituição Federal, que traz inclusive uma proteção mais abrangente.

Via de regra, possuem personalidade jurídica as pessoas, mas essa personalidade não se confunde com a condição de ser humano, pois antigamente houve pessoas, como os escravos, a quem se negava a personalidade, e mesmo nos dias atuais, existem entes personalizados que não são pessoas humanas. ${ }^{4}$

O artigo $2^{\circ}$ do Código Civil destaca que a personalidade civil da pessoa

4 RODRIGUES JUNIOR, Otavio Luiz; MAMEDE, Gladston; ROCHA, Maria Vital da (Coords.). Responsabilidade civil contemporânea: em homenagem a Sílvio de Salvo Venosa. São Paulo: Atlas, 2011, p. 546. 
KIST. Eduardo Lamour. BAGATINI, Júlia. Responsabilidade civil: uma análise acerca das redes sociais. Revista Eletrônica Direito e Política, Programa de Pós-Graduação Stricto Sensu em Ciência Jurídica da UNIVALI, Itajaí, v.11, n.2, º quadrimestre de 2016. Disponível em: www.univali.br/direitoepolitica - ISSN 1980-7791.

se inicia a partir do nascimento com vida, tratando inicialmente das pessoas naturais ou físicas, contudo, não podemos esquecer das pessoas não humanas, como as pessoas jurídicas, que também possuem relevância jurídica a partir de sua existência.

"Muito embora existam duas correntes doutrinárias sobre o início da personalidade humana, a natalista e a concepcionista ${ }^{5}$, o sistema positivo nacional adotou a primeira, que reconhece o início da personalidade no nascimento com vida $[\ldots]^{\prime \prime}{ }^{6}$

Assim, a personalidade jurídica seria o reconhecimento da existência de um ente, concedendo três atributos ao mesmo, o nome, a capacidade e os direitos inerentes à personalidade. Os direitos em destaque, então, são aqueles que o ente adquire apenas por existir, independentemente de outros requisitos. ${ }^{7}$

Esses direitos configuram uma gama de poderes pertencentes ao ente

5 "[...] o nascimento com vida não é o marco inicial para o alcance dos direitos patrimoniais, mas apenas consolida os mesmos, na medida em que passa a se tornar perfeita a possibilidade de defendê-los. Quanto aos direitos da personalidade referente à vida, à integridade física, à honra e à imagem, estes seriam atributos do nascituro desde o momento da sua concepção, razão pela qual deve ser protegido pela possibilidade de indenização pelos danos que lhes sejam causados. A tese sustentada por Silmara Juny Chinellato restou acompanhada por diversos doutrinadores, como Pontes de Miranda, Rubens Limongi França, Flávio Tartuce, Gustavo Rene Nicolau, Renan Lotufo e Maria Helena Diniz. Verifica-se, pois, que a citada teoria é a que prevalece entre os autores contemporâneos do Direito Civil Brasileiro, os quais conferem direitos efetivos e reconhecidos ao nascituro desde 0 momento da sua concepção". (ASFOR, Ana Paula. Do início da personalidade civil. Jus Navigandi, Teresina, ano 18, n. 3629. 8 jun. 2013. Disponível em: <http://jus.com.br/artigos/24650/do-inicio-da-personalidade-civil>. Acesso em: 19 nov. 2015).

6 PAIVA, J. A. Almeida. "A personalidade civil do homem começa com o nascimento com vida". Revista Consultor Jurídico, 24 nov. 2003. Disponível em: <www.conjur.com.br/2003-nov-24/personalidade_civil_comeca_nascimento_vida>. Acesso em: 19 nov. 2015.

7 RODRIGUES JUNIOR, Otavio Luiz; MAMEDE, Gladston; ROCHA, Maria Vital da (Coords.). Responsabilidade civil contemporânea: em homenagem a Sílvio de Salvo Venosa. p. 547. 
KIST. Eduardo Lamour. BAGATINI, Júlia. Responsabilidade civil: uma análise acerca das redes sociais. Revista Eletrônica Direito e Política, Programa de Pós-Graduação Stricto Sensu em Ciência Jurídica da UNIVALI, Itajaí, v.11, n.2, º quadrimestre de 2016. Disponível em: www.univali.br/direitoepolitica - ISSN 1980-7791.

para participar das relações jurídicas, entretanto, há quem diga que a personalidade não constitui um direito propriamente dito, pensamento melhor compreendido nas palavras de Maria Helena Diniz:

A personalidade não é um direito, de modo que seria errôneo afirmar que o ser humano tem direito à personalidade. A personalidade é que apóia os direitos e deveres que dela irradiam, é o objeto de direito, é o primeiro bem da pessoa, que lhe pertence como primeira utilidade, para que ela possa ser o que é, para sobreviver e se adaptar às condições do ambiente em que se encontra, servindo-lhe de critério para aferir, adquirir e ordenar outros bens. ${ }^{8}$

Os direitos da personalidade são tratados como direitos comuns da existência, como autorizações concedidas pela norma jurídica a cada pessoa, para defender os bens que recebeu naturalmente, de forma direta. Eles são inerentes à personalidade, como por exemplo o direito à vida, à liberdade, à saúde, à honra, à intimidade, e à privacidade.

Tais direitos possuem como base a dignidade humana, isto é, são a consequência do reconhecimento do princípio da dignidade, e a ela estão ligados. ${ }^{9}$ Entretanto, abrangem também outros aspectos da pessoa humana, não diretamente ligados à sua dignidade, como os chamados novos direitos da personalidade, que seriam a imagem, 0 nome, a reputação, sentimentos, relações afetivas, hábitos, gostos, convicções políticas e religiosas, entre outros. ${ }^{10}$

Dessa forma, os direitos da personalidade podem ser praticados em diferentes aspectos e violados pelos mais variados meios, mas irão

8 DINIZ, Maria Helena. Curso de direito civil brasileiro, 70 volume: responsabilidade civil. 21 ed. rev. e atual. São Paulo: Saraiva, 2007, p. 72.

9 SOARES, Flaviana Rampazzo. Responsabilidade civil por dano existencial. Porto Alegre: Livraria do Advogado Editora, 2009, p. 35.

10 CAVALIERI FILHO, Sérgio. Programa de responsabilidade civil. 10 ed. São Paulo: Atlas, 2012, p. 90. 
KIST. Eduardo Lamour. BAGATINI, Júlia. Responsabilidade civil: uma análise acerca das redes sociais. Revista Eletrônica Direito e Política, Programa de Pós-Graduação Stricto Sensu em Ciência Jurídica da UNIVALI, Itajaí, v.11, n.2, º quadrimestre de 2016. Disponível em: www.univali.br/direitoepolitica - ISSN 1980-7791.

proteger principalmente a dignidade humana, por meio de punições que devem ser pretendidas pelo ofendido.

Sua conceituação, a partir da personalidade de cada um, é tarefa difícil para a doutrina, devido aos avanços tecnológicos que posicionam a pessoa humana em situações jamais previstas, como nos casos de responsabilidade civil da reprodução assistida, da clonagem, e vários outros casos que alteraram o cotidiano da sociedade. ${ }^{11}$

Na mesma linha de pensamento, os direitos em questão configuram requisitos essenciais da pessoa, "[...] cujo reconhecimento jurídico resulta de uma contínua marcha de conquistas históricas. No decorrer dos últimos séculos, o tema foi tratado sob diferentes enfoques e distintas denominações". ${ }^{12}$

A personalidade, portanto, é um conjunto de atributos, como a vida, a honra, o nome, a imagem, a dignidade, todos considerados parte de um objeto, formador da pessoa. Os direitos da personalidade, por sua vez, seriam aqueles derivados de tais atributos, buscando sempre a proteção e o respeito da pessoa e sua dignidade. Esse conceito atual, de que esses valores são parte da pessoa, é de grande valia para que, não somente o ser humano, mas também outros entes possam ser compreendidos e buscarem a igualdade no meio em que estão inseridos.

Tais direitos possuem um caráter extrapatrimonial, que decorre principalmente de não existir avaliação pecuniária, pois há apenas uma compensação que não se equipara ao ressarcimento por dinheiro.

\footnotetext{
${ }^{11}$ FROTA, Pablo Malheiros da Cunha. Danos morais e a pessoa jurídica. São Paulo: Método, 2008, p. 117.

12 SCHREIBER, Anderson. Direitos da personalidade. 2 ed. São Paulo: Atlas, 2013, p. 13.
} 
KIST. Eduardo Lamour. BAGATINI, Júlia. Responsabilidade civil: uma análise acerca das redes sociais. Revista Eletrônica Direito e Política, Programa de Pós-Graduação Stricto Sensu em Ciência Jurídica da UNIVALI, Itajaí, v.11, n.2, º quadrimestre de 2016. Disponível em: www.univali.br/direitoepolitica - ISSN 1980-7791.

São gerais, pois concedidos aos seres humanos apenas por existirem ${ }^{13}$, e absolutos, por serem oponíveis contra todos, desde que respeitando outros direitos de patamar igual ou superior. ${ }^{14}$

Os direitos da personalidade também são tratados como intransmissíveis e inalienáveis, isto é, não podem ser transmitidos nem alienados a outrem, seja por ato entre vivos, ou em razão da morte do seu titular.

Constituem direitos exclusivos do referido titular, não podendo ser cedidos, doados, emprestados, vendidos ou recebidos por herança. É importante lembrar também, sobre o fato de alguém atentar contra a personalidade de pessoa já falecida, pois não resta dúvida de que, com a morte, a personalidade em sentido subjetivo se extingue, a existência da pessoa cessa. Seu caráter objetivo, no entanto, possui solução delicada, mas o Código Civil, em boa hora, trouxe uma saída prática, no parágrafo único do artigo 12 , determinando aos herdeiros a legitimação para pleitear as medidas extintivas da lesão aos direitos da personalidade do morto. ${ }^{15}$

Ainda, é possível classificar tais direitos como irrenunciáveis e indisponíveis, não esquecendo que essa indisponibilidade é considerada relativa, já que os direitos da personalidade sofrem limitação voluntária, desde que não seja permanente nem geral, conforme o disposto no Enunciado n. 4, da I Jornada de Direito Civil, organizada pelo Centro de Estudos Judiciários da Justiça Federal, se opondo ao disposto no artigo 11 do Código Civil, no sentido de que o

${ }^{13}$ FROTA, Pablo Malheiros da Cunha. Danos morais e a pessoa jurídica. p. 136.

${ }^{14}$ SOARES, Flaviana Rampazzo. Responsabilidade civil por dano existencial. p. 36.

${ }^{15}$ SCHREIBER, Anderson. Direitos da personalidade. p. 24. 
KIST. Eduardo Lamour. BAGATINI, Júlia. Responsabilidade civil: uma análise acerca das redes sociais. Revista Eletrônica Direito e Política, Programa de Pós-Graduação Stricto Sensu em Ciência Jurídica da UNIVALI, Itajaí, v.11, n.2, º quadrimestre de 2016. Disponível em: www.univali.br/direitoepolitica - ISSN 1980-7791.

seu exercício não pode sofrer essa limitação.

Como exemplo, há o caso do reality show denominado Big Brother Brasil, perfazendo uma clara interferência no direito à privacidade, ferindo a personalidade humana, mas contando com o consentimento dos envolvidos. Resta saber se esse consentimento é suficiente para tornar lícita uma lesão aos direitos da personalidade, já que o artigo 11, do Código Civil, trataria o caso de forma negativa, pois o retrato histórico justifica o receio do legislador, demonstrando que, "deixados inteiramente livres, os homens acabam por renunciar aos seus direitos mais essenciais, 'concordando', por força da necessidade, com situações intoleráveis". ${ }^{16}$

Essa preocupação do legislador, não se trata de algo ultrapassado, tendo em vista os atuais acontecimentos, comprovando que o ser humano é capaz de qualquer coisa para suprir suas necessidades, como a venda de órgãos, que, mesmo proibida por lei, ocorre de forma clandestina.

Portanto, o legislador acertou em parte, já que os direitos da personalidade não podem, de fato, serem renunciados, devendo o seu titular conviver com os mesmos, não podendo se despedir deles de forma geral ou definitiva. Por outro lado, errou ao vedar toda e qualquer limitação voluntária, vedação esta que ocasionaria a ilicitude não apenas dos reality shows, mas de atos mais comuns como furar a orelha, lutar boxe ou disseminar informações pessoais em redes sociais. Há uma série de casos não previstos em lei, mas socialmente admitidos, em que as pessoas desejam e consentem limitar, precisamente, a atividade de algum atributo da própria

${ }^{16}$ SCHREIBER, Anderson. Direitos da personalidade. p. 26. 
KIST. Eduardo Lamour. BAGATINI, Júlia. Responsabilidade civil: uma análise acerca das redes sociais. Revista Eletrônica Direito e Política, Programa de Pós-Graduação Stricto Sensu em Ciência Jurídica da UNIVALI, Itajaí, v.11, n.2, º quadrimestre de 2016. Disponível em: www.univali.br/direitoepolitica - ISSN 1980-7791.

personalidade. ${ }^{17}$

É o que ocorre nas decisões concedidas favoravelmente em razão das denominadas Testemunhas de Jeová18, pessoas que por motivos religiosos se recusam a receber transfusão de sangue, tomando a dignidade da pessoa humana como um fundamento constitucional e norteador de tais jurisprudências.

A prática vai exigir do jurista uma análise de cada situação concreta, pois a ordem jurídica não é contra ou a favor da vontade, apenas a favor da realização da pessoa, devendo admitir, para atingir tal realização, a autolimitação de certos direitos. Essa diferenciação, no caso concreto, é muito complicada, exigindo cautela redobrada.

Já tratando especificamente dos direitos da personalidade que podem sofrer violações na internet ou nas redes sociais, é sempre necessário tomar certos cuidados, que deveriam estar intrinsecamente envolvidos

17 SCHREIBER, Anderson. Direitos da personalidade. p. 26 e 27.

18 EMENTA: AGRAVO DE INSTRUMENTO. DIREITO PRIVADO NÃO ESPECIFICADO. TESTEMUNHA DE JEOVÁ. TRANSFUSÃO DE SANGUE. DIREITOS FUNDAMENTAIS. LIBERDADE DE CRENÇA E DIGNIDADE DA PESSOA HUMANA. PREVALÊNCIA. OPÇÃO POR TRATAMENTO MÉDICO QUE PRESERVA A DIGNIDADE DA RECORRENTE. A decisão recorrida deferiu a realização de transfusão sanguínea contra a vontade expressa da agravante, a fim de preservar-Ihe a vida. A postulante é pessoa capaz, está lúcida e desde o primeiro momento em que buscou atendimento médico dispôs, expressamente, a respeito de sua discordância com tratamentos que violem suas convicções religiosas, especialmente a transfusão de sangue. Impossibilidade de ser a recorrente submetida a tratamento médico com o qual não concorda e que para ser procedido necessita do uso de força policial. Tratamento médico que, embora pretenda a preservação da vida, dela retira a dignidade proveniente da crença religiosa, podendo tornar a existência restante sem sentido. Livre arbítrio. Inexistência do direito estatal de "salvar a pessoa dela própria", quando sua escolha não implica violação de direitos sociais ou de terceiros. Proteção do direito de escolha, direito calcado na preservação da dignidade, para que a agravante somente seja submetida a tratamento médico compatível com suas crenças religiosas. AGRAVO PROVIDO. (RIO GRANDE DO SUL, Tribunal de Justiça. Agravo de Instrumento No 70032799041, Décima Segunda Câmara Cível. Relator: Cláudio Baldino Maciel, Porto Alegre, 11 mar. 2010.2 Disponível em: <http://www1.tjrs.jus.br/site_php/consulta/download/exibe_documento_att.php?a no $=2010 \&$ codigo $=1304322>$. Acesso em: 19 nov. 2015). 
KIST. Eduardo Lamour. BAGATINI, Júlia. Responsabilidade civil: uma análise acerca das redes sociais. Revista Eletrônica Direito e Política, Programa de Pós-Graduação Stricto Sensu em Ciência Jurídica da UNIVALI, Itajaí, v.11, n.2, º quadrimestre de 2016. Disponível em: www.univali.br/direitoepolitica - ISSN 1980-7791.

nesses meios, como o respeito ao próximo.

Os direitos da personalidade que podem ser lesados com maior frequência nesses meios de comunicação virtual, são a honra, a imagem e a vida privada, esta, abrangendo a privacidade, a intimidade e o segredo. ${ }^{19}$

Em disparidade a esses direitos, nos ambientes de comunicação mais avançados também está presente a liberdade de expressão, que deve sempre ser utilizada com cautela, isto é, seu uso não é proibido, mas é imprescindível uma utilização consciente, a fim de evitar possíveis danos que, se consumados, terão respaldo da responsabilidade civil para sua efetiva reparação.

\section{A RESPONSABILIDADE CIVIL POR DANOS ADVINDOS DO MAU USO DAS REDES SOCIAIS}

A cada dia que passa, a internet vem se tornando o "carro chefe" em matéria de comunicação no mundo inteiro, principalmente por meio das redes sociais, entre elas o Facebook, tornando livre o acesso de publicações sobre a vida dos usuários, seus preceitos, gostos, ideias, bem como a possibilidade de adicionar pessoas, postar fotos ou informações, entre várias outras modalidades de interação. ${ }^{20}$

É certo que, juntamente com essa evolução, por vezes vislumbrada como algo incontrolável, surgem também conflitos, muitos deles nos

19 SILVA, Regina Beatriz Tavares da; SANTOS, Manoel J. Pereira dos (Coords.). Responsabilidade civil: responsabilidade civil na internet e nos demais meios de comunicação. 2 ed. São Paulo: Saraiva, 2012, p. 35.

20 TRENTIN, Taíse Rabelo Dutra; TRENTIN, Sandro Seixas. Internet: publicações ofensivas em redes sociais e o direito à indenização por danos morais. REDESG Revista Direitos Emergentes na Sociedade Global, Santa Maria. v. 1, n. 1, jan.jun. 2012, p. 81. Disponível em: <cascavel.cpd.ufsm.br/revistas/ojs2.2.2/index.php/REDESG/article/viewFile/6263/pdf>. Acesso em: 19 nov. 2015. 
KIST. Eduardo Lamour. BAGATINI, Júlia. Responsabilidade civil: uma análise acerca das redes sociais. Revista Eletrônica Direito e Política, Programa de Pós-Graduação Stricto Sensu em Ciência Jurídica da UNIVALI, Itajaí, v.11, n.2, º quadrimestre de 2016. Disponível em: www.univali.br/direitoepolitica - ISSN 1980-7791.

próprios meios de interatividade, confirmando o caráter aberto dos meios tecnológicos e suas implicações sociais.

As redes sociais, por sua vez, possuem aspectos positivos e negativos, ou seja, ao passo em que são uma prática maneira de se comunicar com pessoas de todos os lugares e pelas mais variadas ferramentas, muitos as utilizam apenas para denegrir os valores humanos, atacando os atributos da personalidade.

O ambiente virtual se tornou muito propício para condutas odiosas e divergentes, necessitando alguma forma de intervenção, de um controle maior sobre as ações realizadas. É o que ocorreu no "caso Cicarelli", em que um cinegrafista amador flagrou a modelo em momentos de intimidade com seu namorado, sendo tal cena filmada e rapidamente propagada na rede mundial de computadores, tornando impossível qualquer tentativa de controlar o uso danoso da imagem. Outra conduta reprovável, ocorreu no caso em que a atriz Carolina Dieckmann teve suas fotos íntimas disseminadas nas redes sociais, ferindo sua intimidade. ${ }^{21}$

Dessa forma, é importante destacar o disposto na Constituição Federal, em seu artigo 50, inciso $X$, possibilitando a indenização pela violação da intimidade, da vida privada, da honra e da imagem das pessoas, algo frequentemente observado nas redes sociais. O Código Civil, em seu artigo 186, também faz menção ao tema, no qual o indivíduo que, por ação ou omissão voluntária, negligência ou imprudência, lesar direito e causar prejuízo a outrem, mesmo que apenas moral, pratica

21 TRENTIN, Taíse Rabelo Dutra; TRENTIN, Sandro Seixas. Internet: publicações ofensivas em redes sociais e o direito à indenização por danos morais. REDESG Revista Direitos Emergentes na Sociedade Global, Santa Maria. v. 1, n. 1, jan.jun. 2012, p. 83 e 84. Disponível em: <cascavel.cpd.ufsm.br/revistas/ojs2.2.2/index.php/REDESG/article/viewFile/6263/pdf>. Acesso em: 19 nov. 2015. 
KIST. Eduardo Lamour. BAGATINI, Júlia. Responsabilidade civil: uma análise acerca das redes sociais. Revista Eletrônica Direito e Política, Programa de Pós-Graduação Stricto Sensu em Ciência Jurídica da UNIVALI, Itajaí, v.11, n.2, º quadrimestre de 2016. Disponível em: www.univali.br/direitoepolitica - ISSN 1980-7791.

ato ilícito.

Devido ao caráter de liberdade oferecido aos usuários, tanto na internet quanto nas redes sociais, podendo os mesmos publicarem o que quiserem, quando quiserem, é o que geralmente ocorre, afinal, tais publicações podem ensejar informações não verdadeiras, ou com finalidade de denegrir a imagem de outrem, lesando diretamente seus direitos da personalidade.

Vale destacar, no âmbito da internet e das redes sociais, o que é considerado como ilícito ou não. Ilícita seria a informação digital que, uma vez disseminada na rede, viola direitos de outrem ou uma disposição destinada a proteger interesses alheios. Um texto sobre determinada pessoa, por exemplo, ofendendo seu nome, será ilícito quando publicado e divulgado por meio das redes sociais, mas não enquanto estiver guardado no disco rígido do computador do seu autor. O mesmo se aplica para um filme que é adquirido pelo consumidor, ato aceitável, mas que pode se tornar ilícito se esse filme for disponibilizado a vários usuários da rede, pelas ferramentas possíveis. ${ }^{22}$

Outra prática inadequada dos referidos meios, é a criação de um perfil falso, geralmente para tirar proveito de um terceiro, ou se passar por outrem, o que dificulta a identificação direta daquele que está praticando a conduta reprovável.

${ }^{22}$ COSTA, João Pedro Fachana Cardoso Moreira da. A responsabilidade civil pelos conteúdos ilícitos colocados e difundidos na internet: em especial da responsabilidade pelos conteúdos gerados por utilizadores. Dissertação (Mestrado em Direito). Universidade do Porto. Portugal, 2011, p. 43. Disponível em: <http://repositorio-aberto.up.pt/bitstream/10216/63893/2/

Joo\%20FachanaA $\% 20$ responsabilidade $\% 20$ civil\%20pelos $\% 20$ contedos $\% 20$ ilcitos $\%$ 20colocados\%20e\%20difundidos\%20na\%20Internet.pdf>. Acesso em: 19 nov. 2015. 
KIST. Eduardo Lamour. BAGATINI, Júlia. Responsabilidade civil: uma análise acerca das redes sociais. Revista Eletrônica Direito e Política, Programa de Pós-Graduação Stricto Sensu em Ciência Jurídica da UNIVALI, Itajaí, v.11, n.2, º quadrimestre de 2016. Disponível em: www.univali.br/direitoepolitica - ISSN 1980-7791.

Não menos importante, o chamado cyberbullying engloba as mensagens via internet, em que o autor se faz passar por outra pessoa para proferir palavras desagradáveis e espalhar intrigas, além da utilização das redes sociais para expor as pessoas de forma vexatória. É o caso de fotografias tiradas, muitas vezes sem o consentimento da vítima, e alteradas por meio de montagens constrangedoras, incluindo até ofensas ou comentários sexistas e racistas, antes de serem postadas. $^{23}$

Esse cyberbullying se consuma quando o autor da conduta utiliza os mais avançados recursos de tecnologia na internet, com intenção de constranger e humilhar as suas vítimas, seja qual for o motivo para tal ação.

Muitas vezes, o acesso às informações das pessoas não é definido como privado, opção permitida nesses meios de comunicação, e a inclusão digital tem sua parte nisso, pois ainda há um grande número de usuários leigos, que acabam se tornando vulneráveis nas mãos daqueles que procuram exercer apenas o uso inadequado dos ambientes virtuais.

A justiça, no entanto, já está utilizando nos processos as informações provenientes das redes sociais, levando em conta que normalmente são exibidas fotos dos seus usuários, de amigos, familiares, biografias e até mesmo suas rotinas diárias. "Além do mais, muitos usuários sentem a liberdade de dizer o que querem, agindo na maioria das vezes sem pensar e as consequências são inúmeras, pois é como se estivessem pelo mundo gritando em um megafone para todos

${ }^{23}$ BOFF, Salete Oro; REIS, Jorge Renato; REDIN, Giuliana (Orgs.). O direito na era digital: as novas tecnologias de informação e de comunicação. Passo Fundo: IMED, 2011, p. 55. 
KIST. Eduardo Lamour. BAGATINI, Júlia. Responsabilidade civil: uma análise acerca das redes sociais. Revista Eletrônica Direito e Política, Programa de Pós-Graduação Stricto Sensu em Ciência Jurídica da UNIVALI, Itajaí, v.11, n.2, 2o quadrimestre de 2016. Disponível em: www.univali.br/direitoepolitica - ISSN 1980-7791.

ouvirem". 24

Cabe lembrar que essa exposição de informações mal planejada e desenfreada, pode comprometer significativamente a segurança dos usuários em questão, eis que muitos deixam tais informações visíveis a qualquer pessoa que acessar seus perfis.

Os meios de comunicação virtuais trazem tamanha liberdade de expressão, que inúmeros povos assolados por tiranias que duraram décadas os utilizaram com propósito de derrubar seus algozes, como no caso do Egito, no qual as ferramentas Facebook e Twitter contribuíram espantosamente para a deposiçãodo presidente Hosni Mubarak $^{25}$, que estava no poder há mais de trinta anos. ${ }^{26}$

24 OLIVEIRA JÚNIOR, Claudomiro Batista de; FARIAS, Dayane Karla Barros de. A responsabilidade civil em consequência dos atos ilícitos praticados nas redes digitais e o dever de reparação. p. 11. Disponível em: <www.publicadireito.com.br/artigos/?cod=f7f580e11d 00a758>. Acesso em: 19 nov. 2015.

25 A Revolução Egípcia de 2011, também denominada Dias de Fúria, ou Revolução de Lótus, caracteriza importantes manifestações do povo egípcio, além de protestos e atos de violência civil que ocorreram no Egito entre 25 de janeiro e 11 de fevereiro de 2011. Os motivos da revolução foram a violência policial, leis de estado de exceção, altas taxas de desemprego, baixos salários, falta de moradia digna, forte desvalorização da moeda, a violenta corrupção administrativa, falta de liberdade de expressão, além de fatores demográficos decorrentes da superpopulação das regiões do rio Nilo. O principal objetivo era a derrubada do regime ditatorial de Hosni Mubarak, que estava no poder do país desde 1981. Para se ter noção da importância dos meios de comunicação virtuais na referida revolução, após muitos grupos terem sido criados no Facebook, e a situação egípcia exposta amplamente por meio de postagens no Twitter, o governo derrubou os serviços de internet, com propósito de desmembrar a mobilização e impedir o fluxo de notícias para fora do país. Em 11 de fevereiro de 2011, após muitos protestos, ocorre a "Sexta-Feira da Partida", isto é, às 18 horas do horário local, Omar Suleiman, vice-presidente, anuncia a renúncia de Mubarak, deixando o poder nas mãos do Conselho Supremo das Forças Armadas. (PORTO, Gabriella. Revolução Egípcia de 2011. InfoEscola. Disponível em: $<$ www.infoescola.com/historia/revolucao-egipcia-de-2011>. Acesso em: 19 nov. 2015).

26 BRAGA, Diogo de Melo; BRAGA, Marcus de Melo; ROVER, Aires José. Responsabilidade civil das redes sociais no direito brasileiro. In: SID Simposio Argentino de Informática y Derecho. Cordoba, 2011. Anales de las 40 Jornadas Argentinas de Informática, 2011, p. 142-150. Disponível em: <www.egov.ufsc.br/portal/conteudo/publicação-responsabilidade-civil-das-redes- 
KIST. Eduardo Lamour. BAGATINI, Júlia. Responsabilidade civil: uma análise acerca das redes sociais. Revista Eletrônica Direito e Política, Programa de Pós-Graduação Stricto Sensu em Ciência Jurídica da UNIVALI, Itajaí, v.11, n.2, º quadrimestre de 2016. Disponível em: www.univali.br/direitoepolitica - ISSN 1980-7791.

É certo que os usuários desses meios de comunicação devem saber utilizar essa liberdade de maneira consciente, nunca visando prejudicar os bens jurídicos tutelados das outras pessoas, conduta que, nos dias atuais, é claramente reprovável no âmbito da responsabilidade civil, que busca proteger os direitos inerentes à personalidade.

Antes do Marco Civil da Internet, não havia determinação ou um regramento específico para essas relações, tornando a liberdade de expressão ainda maior, e fazendo com que diferentes decisões fossem proferidas. Apesar disso, o que se percebe é que já havia a responsabilização civil daqueles que utilizavam incorretamente os meios virtuais, tanto na esfera geral, quanto nas redes sociais.

Nesse sentido, de acordo com decisão negando provimento ao recurso e mantendo condenação por dano moral, confirmada pela $1^{\text {a }}$ Turma Recursal do Tribunal de Justiça do Distrito Federal e dos Territórios (TJDFT), na apelação cível do Juizado Especial n. 20120710113525ACJ, conforme caso de injúria por parte do réu em conversa na rede social Facebook, temos que:

Pela prova documental coligida aos autos, é possível perceber que recorrido e recorrente possuíam um acordo, o qual foi desfeito e, por isso, gerou insatisfação em ambos. Porém, o réu/recorrente proferiu xingamento capaz de injuriar o autor/recorrido. Não há relevância no fato da conversa não ter sido compartilhada com terceiros, a ofensa é de caráter pessoal. ${ }^{27}$

Mesmo com decisões anteriores e consolidadas responsabilizando civilmente aqueles que utilizavam inadequadamente a internet e as

sociais-no-direito-brasileiro>. Acesso em: 19 nov. 2015.

27 DISTRITO FEDERAL, Tribunal de Justiça. Apelação cível n. 20120710113525ACJ, da $1^{a}$ Turma Recursal dos Juizados Especiais do Distrito Federal. Apelante: R.C.G. Apelado: F.R.L. Relatora: Dra. Wilde Maria Silva Justiniano Ribeiro. Brasília, 05 de março de 2013. Disponível em: <juris.tjdft.jus.br/docjur/660661/660912.doc>. Acesso em: 19 nov. 2015. 
KIST. Eduardo Lamour. BAGATINI, Júlia. Responsabilidade civil: uma análise acerca das redes sociais. Revista Eletrônica Direito e Política, Programa de Pós-Graduação Stricto Sensu em Ciência Jurídica da UNIVALI, Itajaí, v.11, n.2, º quadrimestre de 2016. Disponível em: www.univali.br/direitoepolitica - ISSN 1980-7791.

redes sociais, foi a partir da Lei n. 12.965/2014, com a instituição do denominado Marco Civil da Internet, que, de fato, foi determinado o regramento para a utilização da grande rede.

Vários juristas renomados concordaram com a criação de normas para os meios de comunicação virtual, compostas por preceitos defensores dos direitos fundamentais. Assim, surgiu o Marco Civil da Internet, visando adaptar alguns princípios constitucionais, como a liberdade de expressão, à internet. ${ }^{28}$

Foram estabelecidos, em cinco capítulos, princípios, garantias, deveres e direitos que, se não observados, causarão danos e consequentes responsabilizações, a fim de controlar a questão, principalmente pela liberdade que o meio proporciona.

Portanto, fica claro que tanto antes quanto após a criação do Marco Civil da Internet, aquele que utilizava ou vier a utilizar as redes sociais de maneira inadequada, na forma de precursor da informação, era e será responsabilizado civilmente pelos seus atos. Porém, resta saber se a conduta de terceiros, isto é, por meio do compartilhamento de informações, comentários e curtidas realizadas, pode causar prejuízos, ensejando a responsabilização dos mesmos, e necessitando de reparação.

\section{A RESPONSABILIDADE CIVIL DE TERCEIROS NAS REDES SOCIAIS, PELO COMPARTILHAMENTO DE INFORMAÇÕES, COMENTÁRIOS E CURTIDAS REALIZADAS}

É certo que esses meios de comunicação, envolvendo as redes sociais, possuem como característica a possibilidade de o conteúdo ser

\footnotetext{
28 PAESANI, Liliana Minardi. Direito e internet: liberdade de informação, privacidade e responsabilidade civil. 7 ed. São Paulo: Atlas, 2014, p. 29 e 30.
} 
KIST. Eduardo Lamour. BAGATINI, Júlia. Responsabilidade civil: uma análise acerca das redes sociais. Revista Eletrônica Direito e Política, Programa de Pós-Graduação Stricto Sensu em Ciência Jurídica da UNIVALI, Itajaí, v.11, n.2, º quadrimestre de 2016. Disponível em: www.univali.br/direitoepolitica - ISSN 1980-7791.

adicionado, compartilhado, comentado ou curtido por várias pessoas de diferentes lugares e ao mesmo tempo. Essa variedade de ideias e opiniões pode elevar consideravelmente as chances de contendas e guiar a violação de princípios como os da intimidade, da vida privada, da honra, da imagem, além de outros igualmente importantes.

Ao realizar comentário, compartilhar ou curtir algo ofensivo, portanto, o usuário evidentemente concorda com o conteúdo que está ajudando a publicar, devendo ser responsabilizado civilmente, assim como o precursor da postagem. Dessa maneira, por mais que a liberdade de expressão tenha respaldo constitucional, ela não é absoluta e deve ser utilizada com consciência, evitando ofender outros usuários. ${ }^{29}$

Muitas pessoas não entendem a dimensão das ações que realizam nos meios de comunicação virtuais, às vezes um comentário, um compartilhamento ou o simples curtir parecem tão inofensivos, que são realizados sem o mínimo de consideração e pensamento.

Entretanto, várias são as consequências desses atos, como o caso em que o Poder Judiciário determinou válida a demissão por justa causa de um empregado por curtir uma postagem, feita por um exfuncionário, ofensiva à empresa de motos na qual trabalhava em São Paulo. Determinou a juíza relatora do Tribunal Regional do Trabalho (TRT) da $15^{a}$ região que "a liberdade de expressão não permite ao empregado travar conversas públicas em rede social ofendendo a sócia proprietária da empresa, o que prejudicou de forma definitiva a continuidade de seu pacto laboral $[\ldots]^{\prime \prime} .30$

29 ROVER, Tadeu. Compartilhar ofensa em rede social gera dano moral. Revista Consultor Jurídico. 4 dez. 2013. Disponível em: <www.conjur.com.br/2013-dez04/compartilhar-comentario-inveridico-ou-ofensivo-facebook-gera-dano-moral>. Acesso em: 19 nov. 2015.

${ }^{30}$ GOMES, Helton Simões. Justiça julga válida demissão por justa causa por 'curtida' 
KIST. Eduardo Lamour. BAGATINI, Júlia. Responsabilidade civil: uma análise acerca das redes sociais. Revista Eletrônica Direito e Política, Programa de Pós-Graduação Stricto Sensu em Ciência Jurídica da UNIVALI, Itajaí, v.11, n.2, º quadrimestre de 2016. Disponível em: www.univali.br/direitoepolitica - ISSN 1980-7791.

É importante evidenciar o caso do curtir, que, diferente de comentar ou compartilhar, parece muito menos ofensivo. Não foi o que se verificou no exemplo do empregado que foi demitido, mas com toda a tecnologia existente atualmente, muitas pessoas estão conectadas às redes sociais diretamente por meio de seus celulares, e não se pode deixar de considerar a hipótese de que muitas curtidas ocorrem sem intenção, inúmeras vezes sem ao menos ler o conteúdo da postagem, ou, ainda, apenas por afinidade com a pessoa precursora da informação.

Há quem defenda que o curtir é algo individual, como o desembargador José Roberto Neves Amorim, isto é, algo que não passa do limite da pessoa que está lendo a postagem, não gerando indenização. Por outro lado, o compartilhar aumenta a amplitude das ofensas proferidas contra alguém, o ofensor concorda com o que está propagando, e, dependendo da difusão que for feita, efetivamente causa um dano. ${ }^{31}$

Porém, esse compartilhar pode ser realizado de forma crítica, não concordante com a ofensa, o que também não gera indenização. Essa opção permite que os usuários adicionem uma mensagem personalizada junto ao link da postagem, permitindo então esse compartilhamento crítico. ${ }^{32}$

Nesse sentido, conforme sentença procedente à condenação por danos

no Facebook. G1, São Paulo. 27 jun. 2014. Disponível em: <g1.globo.com/tecnologia/noticia/2014/06/justica-julga-valida-demissao-comjusta-causa-por-curtida-no-facebook.html>. Acesso em: 19 nov. 2015.

31 REDAÇÃO Justificando. Desembargador comenta condenações sobre "curtir" e "compartilhar" conteúdos no Facebook e Secret. Justificando. Disponível em: <justificando.com/2014/09/02/secret/>. Acesso em: 19 nov. 2015.

32 REDAÇÃO Justificando. Desembargador comenta condenações sobre "curtir" e "compartilhar" conteúdos no Facebook e Secret. Justificando. Disponível em: <justificando.com/2014/09/02/secret/>. Acesso em: 19 nov. 2015. 
KIST. Eduardo Lamour. BAGATINI, Júlia. Responsabilidade civil: uma análise acerca das redes sociais. Revista Eletrônica Direito e Política, Programa de Pós-Graduação Stricto Sensu em Ciência Jurídica da UNIVALI, Itajaí, v.11, n.2, º quadrimestre de 2016. Disponível em: www.univali.br/direitoepolitica - ISSN 1980-7791.

morais, determinada pelo Tribunal de Justiça de São Paulo (TJ-SP) ${ }^{33}$, temos um caso de postagem de fotos e textos denegrindo a honra de um profissional veterinário, no qual uma das requeridas realiza o compartilhamento dessas informações, postadas inicialmente pela outra em seu perfil na rede social.

O caso em tela abrange uma cirurgia de castração de uma cadela adulta e, depois de finalizada, os clientes receberam o animal em perfeitas condições, e instruídos dos procedimentos a serem seguidos. Mesmo assim, alguns dias depois a cadela apresentou péssimas condições, e a assistência médica foi recusada por seus responsáveis.

Diante disso, as requeridas publicaram em seus perfis do Facebook fotos do animal, juntamente com textos ofensivos, imputando ao veterinário e autor a responsabilidade pelo estado da cadela, e, assim, denegrindo sua imagem, honra e conduta profissional.

As rés tentaram defesa, e, como uma delas realizou o compartilhamento, alega ilegitimidade passiva, enquanto a outra diz ter tomado tal atitude por indignação perante a situação do animal.

33 EMENTA: RESPONSABILIDADE CIVIL - AÇÃO DE INDENIZAÇÃO POR DANOS MORAIS - RÉS QUE DIVULGARAM TEXTO E FIZERAM COMENTÁRIOS NA REDE SOCIAL "FACEBOOK" SEM SE CERTIFICAREM DA VERACIDADE DOS FATOS ATUAÇÃO DAS REQUERIDAS QUE EVIDENTEMENTE DENEGRIU A IMAGEM DO AUTOR, CAUSANDO-LHE DANOS MORAIS QUE PASSIVEIS DE INDENIZAÇÃO LIBERDADE DE EXPRESSÃO DAS REQUERIDAS (ART. 5, IX, CF) QUE DEVE OBSERVAR O DIREITO DO AUTOR DE INDENIZAÇÃO QUANDO VIOLADA A SUA À HONRA E IMAGEM, DIREITO ESTE TAMBÉM CONSTITUCIONALMENTE DISPOSTO (ART. 5, V , X, CF) - VALOR ARBITRADO A TÍTULO DE DANOS MORAIS QUE DEVE SER REDUZIDO PARA FUGIR DO ENRIQUECIMENTO SEM CAUSA DA PARTE PREJUDICADA, PORÉM, MANTENDO O SEU CARÁTER EDUCACIONAL A FIM DE COIBIR NOVAS CONDUTAS ILÍCITAS - SENTENÇA PARCIALMENTE MODIFICADA, PARA MINORAR O QUANTUM INDENIZATÓRIO. RECURSOS PARCIALMENTE PROVIDOS. (SÃO PAULO, Tribunal de Justiça. Apelação: APL: 40005152120138260451 SP 400051521.2013.8.26.0451. JusBrasil, Relator: Neves Amorim, Data de Julgamento: 26/11/2013, 2a Câmara de Direito Privado, Data de Publicação: 27/11/2013. Disponível em: <http://tj-sp.jusbrasil.com.br/jurisprudencia/118726228/apelacaoapl-4000515212013826 0451-sp-4000515-2120138260451/inteiro-teor118726234>. Acesso em: 19 nov. 2015). 
KIST. Eduardo Lamour. BAGATINI, Júlia. Responsabilidade civil: uma análise acerca das redes sociais. Revista Eletrônica Direito e Política, Programa de Pós-Graduação Stricto Sensu em Ciência Jurídica da UNIVALI, Itajaí, v.11, n.2, º quadrimestre de 2016. Disponível em: www.univali.br/direitoepolitica - ISSN 1980-7791.

Ainda, a ré que realizou o compartilhamento era qualificada como protetora dos animais, exercendo maior influência sobre as pessoas, devendo analisar o caso antes de propagar o mesmo.

Ocorre que em nenhum momento do processo ficou evidente a comprovação da negligência com o animal, por parte do profissional veterinário, ficando provado apenas o compartilhamento de forma ofensiva da notícia inverídica.

Apesar das tentativas de defesa, a decisão foi no sentido de que "é indiscutível a atuação culposa das rés, na medida em que divulgaram texto e fizeram comentários na rede social Facebook em desfavor do autor sem se certificar do que de fato havia ocorrido, ou seja, sem a certeza da culpa do requerente $[\ldots]^{\prime \prime} .34$

Nessa sentença, foi determinada a indenização a ser paga pelas rés, sendo a conduta considerada culposa, mesmo apenas pelo compartilhamento do texto ofensivo. O que ocorre é que muitas pessoas utilizam as redes sociais como um tribunal de exceção, pois condenam e acusam muitas vezes sem pensar nas consequências das condutas que estão exercendo.

Ainda referente ao caso, é importante destacar que:

[...] a partir do momento em que uma pessoa usa sua página pessoal em rede social para divulgar mensagem inverídica ou nela constam ofensas a terceiros, como no caso em questão, por certo são devidos danos morais como entendeu o MM. Juiz a quo. Há responsabilidade dos que "compartilham" mensagens e dos que nelas opinam de forma ofensiva, pelos desdobramentos das

34 SÃo PAULO. Tribunal de Justiça. Processo n. 4000515-21.2013.8.26.0451 2013/000642, da $2^{a}$ Vara Cível. Requerente: L.G.G.L. Requeridas: M. D. e M. R. de F. Dr. Marcos Douglas Veloso Balbino da Silva. Piracicaba, 02 de agosto de 2013. Disponível em: <http://esaj.tjsp.jus.br/cpopg/show.do?processo.codigo $=$ CJ00001A60000\&process o.foro $=451>$. Acesso em: 19 nov. 2015. 
KIST. Eduardo Lamour. BAGATINI, Júlia. Responsabilidade civil: uma análise acerca das redes sociais. Revista Eletrônica Direito e Política, Programa de Pós-Graduação Stricto Sensu em Ciência Jurídica da UNIVALI, Itajaí, v.11, n.2, º quadrimestre de 2016. Disponível em: www.univali.br/direitoepolitica - ISSN 1980-7791.

publicações, devendo ser encarado o uso deste meio de comunicação com mais seriedade e não com o caráter informal que como entendem as rés. ${ }^{35}$

Mesmo havendo apelação, e uma diminuição do valor da indenização, a decisão permaneceu pela responsabilização civil das rés, já que não há dúvidas quanto à conduta inadequada das mesmas, que realizaram postagens e compartilhamentos com o único propósito de ofender a vítima, que teve sua reputação denegrida.

Nesse contexto, é interessante analisar e refletir acerca de outra ponderação do caso em tela:

Se por um lado o meio eletrônico tornou mais simples a comunicação entre as pessoas, facilitando também a emissão de opinião, sendo forte ferramenta para debates em nossa sociedade e para denúncias de inúmeras injustiças que vemos em nosso dia-a-dia, por outro lado, trouxe também, a divulgação desenfreada de mensagens que não condizem com a realidade e atingem um número incontável de pessoas, além da manifestação precipitada e equivocada sobre os fatos, dificultando o direito de resposta e reparação do dano causado aos envolvidos. ${ }^{36}$

Portanto, a atual jurisprudência determina a responsabilidade civil daqueles que praticam os atos de divulgação, disseminação, compartilhamento, comentários e curtidas no que diz respeito ao

35 SÃO PAULO, Tribunal de Justiça. Apelação: APL: 40005152120138260451 SP 4000515-21.2013.8.26.0451. JusBrasil, Relator: Neves Amorim, Data de Julgamento: 26/11/2013, 2a Câmara de Direito Privado, Data de Publicação: 27/11/2013. Disponível em: <http://tjsp.jusbrasil.com.br/jurisprudencia/118726228/apelacao-apl-

40005152120138260451-sp-40005 15-2120138260451/inteiro-teor-118726234>. Acesso em: 19 nov. 2015.

36 SÃO PAULO, Tribunal de Justiça. Apelação: APL: 40005152120138260451 SP 4000515-21.2013.8.26.0451. JusBrasil, Relator: Neves Amorim, Data de Julgamento: 26/11/2013, 2a Câmara de Direito Privado, Data de Publicação: 27/11/2013. Disponível em: <http://tjsp.jusbrasil.com.br/jurisprudencia/118726228/apelacao-apl40005152120138260451-sp-40005 15-2120138260451/inteiro-teor-118726234>. Acesso em: 19 nov. 2015. 
KIST. Eduardo Lamour. BAGATINI, Júlia. Responsabilidade civil: uma análise acerca das redes sociais. Revista Eletrônica Direito e Política, Programa de Pós-Graduação Stricto Sensu em Ciência Jurídica da UNIVALI, Itajaí, v.11, n.2, º quadrimestre de 2016. Disponível em: www.univali.br/direitoepolitica - ISSN 1980-7791.

conteúdo ofensivo nas redes sociais, ainda que o campo do curtir apresente divergências.

É certa e possível, então, a responsabilização direta do terceiro que cause danos por meio de seus atos, enquanto o administrador do espaço deveria ser responsabilizado pelas ações desse terceiro apenas em casos de não cooperação judicial, como a não remoção de conteúdo ofensivo postado, ou até mesmo o não fornecimento de dados que o identifiquem. ${ }^{37}$

Dessa forma, inúmeras postagens são enviadas todos os dias, seja na internet, seja nas redes sociais, contudo, havendo ofensa aos atributos inerentes da personalidade, podem ser responsabilizados não apenas os autores da ofensa, mas também os que contribuíram para a sua divulgação. ${ }^{38}$

Por fim, é possível verificar que aquele considerado precursor da informação responderá civilmente na medida dos seus atos, enquanto o usuário que compartilha informações realiza comentários ou curtidas, com ressalva para este último, a partir do momento que pratica qualquer desses atos, concorda com a informação ou ideia veiculada na primeira postagem, e a toma para si, passando a ser também responsável na esfera civil pelos danos consequentes de sua conduta, devendo repará-los de maneira a buscar a equidade e a justiça na internet e nas redes sociais, proporcionando um ambiente melhor e

37 ZAGO, Gabriela da Silva. A possibilidade de responsabilização civil de terceiros por comentários na internet. Revista Anagrama: Revista Científica Interdisciplinar da Graduação, São Paulo, ano 4 - edição 1, set.-nov. 2010, p. 13. Disponível em: <www.usp.br/anagrama/Zago_ responsabilizacaocivil.pdf>. Acesso em: 19 nov. 2015.

38 GONÇALVES, Carlos Roberto. Direito civil brasileiro, volume 4: responsabilidade civil. 7 ed. São Paulo: Saraiva, 2012, p. 74. 
KIST. Eduardo Lamour. BAGATINI, Júlia. Responsabilidade civil: uma análise acerca das redes sociais. Revista Eletrônica Direito e Política, Programa de Pós-Graduação Stricto Sensu em Ciência Jurídica da UNIVALI, Itajaí, v.11, n.2, º quadrimestre de 2016. Disponível em: www.univali.br/direitoepolitica - ISSN 1980-7791.

mais agradável para a navegação de todos os usuários.

\section{CONSIDERAÇÕES FINAIS}

Tanto antes quanto após o Marco Civil da Internet, aquele considerado precursor da informação era e será responsabilizado civilmente, na medida dos prejuízos causados. Porém, é importante determinar a possibilidade de responsabilização civil de terceiros, ou seja, pelo compartilhamento de informações, comentários e curtidas realizadas.

Portanto, conforme caso analisado e julgado pelo TJSP, com processo n. 4000515-21.2013.8.26.0451, no qual ocorreu uma postagem de fotos e textos denegrindo a honra e conduta de profissional veterinário, em que uma das requeridas realiza o compartilhamento dessas informações, postadas inicialmente pela outra em seu perfil na rede social Facebook, ficou determinada a sentença procedente à condenação, por danos morais, igualmente contra ambas as rés, mesmo que uma delas tenha apenas realizado o compartilhamento.

Diante da pesquisa realizada, e de outras análises na doutrina e jurisprudência, é possível constatar que é certa e possível a responsabilização civil de terceiros, pelos atos que aumentem a amplitude da ofensa proferida, como o compartilhamento de informações, comentários e curtidas realizadas, com atenção para esta última conduta, que apresenta divergências.

Esse, de fato, é um grande passo a fim de buscar a reparação do dano causado pelo ofensor que não seja o precursor da informação, buscando a equidade e a justiça nos novos meios de relacionamento, mais propriamente as redes sociais, estabelecendo um ambiente melhor e mais seguro para todos os usuários.

\section{REFERÊNCIAS DAS FONTES CITADAS}


KIST. Eduardo Lamour. BAGATINI, Júlia. Responsabilidade civil: uma análise acerca das redes sociais. Revista Eletrônica Direito e Política, Programa de Pós-Graduação Stricto Sensu em Ciência Jurídica da UNIVALI, Itajaí, v.11, n.2, º quadrimestre de 2016. Disponível em: www.univali.br/direitoepolitica - ISSN 1980-7791.

ASFOR, Ana Paula. Do início da personalidade civil. Jus Navigandi, Teresina, ano 18, n. 3629. 8 jun. 2013. Disponível em: <http://jus.com.br/artigos/24650 /do-inicio-da-personalidade-civil>. Acesso em: 19 nov. 2015.

BOFF, Salete Oro; REIS, Jorge Renato; REDIN, Giuliana (Orgs.). 0 direito na era digital: as novas tecnologias de informação e de comunicação. Passo Fundo: IMED, 2011.

BRAGA, Diogo de Melo; BRAGA, Marcus de Melo; ROVER, Aires José. Responsabilidade civil das redes sociais no direito brasileiro. In: SID - Simposio Argentino de Informática y Derecho. Cordoba, 2011. Anales de las 40 Jornadas Argentinas de Informática, 2011, p. 142150. Disponível em: <www.egov.ufsc.br/portal/conteudo/publicaçãoresponsabilidade-civil-das-redes-sociais-no-direito-brasileiro>. Acesso em: 19 nov. 2015.

CAVALIERI FILHO, Sérgio. Programa de responsabilidade civil. 10 ed. São Paulo: Atlas, 2012.

COSTA, João Pedro Fachana Cardoso Moreira da. A responsabilidade civil pelos conteúdos ilícitos colocados e difundidos na internet: em especial da responsabilidade pelos conteúdos gerados por utilizadores. Dissertação (Mestrado em Direito). Universidade do Porto. Portugal, 2011, p. 43. Disponível em: <http://repositorioaberto.up.pt/bitstream/10216/63893/2/Joo\%20FachanaA\%20respons abilidade $\% 20$ civil\%20pelos $\% 20$ contedos $\% 20$ ilcitos $\% 20$ colocados $\% 20$ e\%20difundidos\%20na\%20Internet.pdf>. Acesso em: 19 nov. 2015.

DINIZ, Maria Helena. Curso de direito civil brasileiro, $7^{\circ}$ volume: responsabilidade civil. 21 ed. rev. e atual. São Paulo: Saraiva, 2007.

DISTRITO FEDERAL, Tribunal de Justiça. Apelação cível n. 20120710113525ACJ, da $1^{\text {a }}$ Turma Recursal dos Juizados Especiais do Distrito Federal. Apelante: R.C.G. Apelado: F.R.L. Relatora: Dra. Wilde Maria Silva Justiniano Ribeiro. Brasília, 05 de março de 2013. Disponível em: <juris.tjdft.jus.br/docjur/660661/660912.doc>. Acesso em: 19 nov. 2015.

FROTA, Pablo Malheiros da Cunha. Danos morais e a pessoa jurídica. São Paulo: Método, 2008.

GOMES, Helton Simões. Justiça julga válida demissão por justa causa por 'curtida' no Facebook. G1, São Paulo. 27 jun. 2014. Disponível em: <g1.globo.com/tecnologia/noticia/2014/06/justica-julga-validademissao-com-justa-causa-por-curtida-no-facebook.html>. Acesso em: 19 nov. 2015. 
KIST. Eduardo Lamour. BAGATINI, Júlia. Responsabilidade civil: uma análise acerca das redes sociais. Revista Eletrônica Direito e Política, Programa de Pós-Graduação Stricto Sensu em Ciência Jurídica da UNIVALI, Itajaí, v.11, n.2, º quadrimestre de 2016. Disponível em: www.univali.br/direitoepolitica - ISSN 1980-7791.

GONÇALVES, Carlos Roberto. Direito civil brasileiro, volume 4: responsabilidade civil. 7 ed. São Paulo: Saraiva, 2012.

OLIVEIRA JÚNIOR, Claudomiro Batista de; FARIAS, Dayane Karla Barros de. A responsabilidade civil em consequência dos atos ilícitos praticados nas redes digitais e o dever de reparação. $p$. 11. Disponível

em:

$<$ www.publicadireito.com.br/artigos/?cod=f7f580e11d $00 a 758>$.

Acesso em: 19 nov. 2015.

PAESANI, Liliana Minardi. Direito e internet: liberdade de informação, privacidade e responsabilidade civil. 7 ed. São Paulo: Atlas, 2014.

PAIVA, J. A. Almeida. "A personalidade civil do homem começa com o nascimento com vida". Revista Consultor Jurídico, 24 nov. 2003. Disponível em: <www.conjur.com.br/2003-nov24/personalidade_civil_comeca_nascimento_vida>. Acesso em: 19 nov. 2015.

PORTO, Gabriella. Revolução Egípcia de 2011. InfoEscola. Disponível em: <www.infoescola.com/historia/revolucao-egipcia-de-2011>. Acesso em: 19 nov. 2015.

REDAÇÃO Justificando. Desembargador comenta condenações sobre "curtir" e "compartilhar" conteúdos no Facebook e Secret. Justificando. Disponível em: <justificando.com/2014/09/02/secret/>. Acesso em: 19 nov. 2015.

RIO GRANDE DO SUL, Tribunal de Justiça. Agravo de Instrumento No 70032799041, Décima Segunda Câmara Cível. Relator: Cláudio Baldino Maciel, Porto Alegre, 11 mar. 2010. Disponível em: <http://www1.tjrs.jus.br/site_php/consulta/download/exibe_docume nto_att.php?ano=2010\&codigo $=1304322>$. Acesso em: 19 nov. 2015 .

RODRIGUES JUNIOR, Otavio Luiz; MAMEDE, Gladston; ROCHA, Maria Vital da (Coords.). Responsabilidade civil contemporânea: em homenagem a Sílvio de Salvo Venosa. São Paulo: Atlas, 2011.

ROVER, Tadeu. Compartilhar ofensa em rede social gera dano moral. Revista Consultor Jurídico. 4 dez. 2013. Disponível em: $<w w w . c o n j u r . c o m . b r / 2013-d e z-04 / c o m p a r t i l h a r-c o m e n t a r i o-$ inveridico-ou-ofensivo-facebook-gera-dano-moral>. Acesso em: 19 nov. 2015.

SÃO PAULO, Tribunal de Justiça. Apelação: APL: 40005152120138260451 SP 4000515-21.2013.8.26.0451. JusBrasil, Relator: Neves Amorim, Data de Julgamento: 26/11/2013, 2a Câmara 
KIST. Eduardo Lamour. BAGATINI, Júlia. Responsabilidade civil: uma análise acerca das redes sociais. Revista Eletrônica Direito e Política, Programa de Pós-Graduação Stricto Sensu em Ciência Jurídica da UNIVALI, Itajaí, v.11, n.2, º quadrimestre de 2016. Disponível em: www.univali.br/direitoepolitica - ISSN 1980-7791.

de Direito Privado, Data de Publicação: 27/11/2013. Disponível em: <http://tj-sp.jusbrasil.com.br/jurisprudencia/118726228/apelacaoapl-40005152120138260451-sp-40005 15-2120138260451/inteiroteor-118726234>. Acesso em: 19 nov. 2015.

\section{Processo n. 4000515-21.2013.8.26.0451}

2013/000642, da 2a Vara Cível. Requerente: L.G.G.L. Requeridas: M. D. e M. R. de F. Dr. Marcos Douglas Veloso Balbino da Silva. Piracicaba, 02 de agosto de 2013. Disponível em: <http://esaj.tjsp.jus.br/cpopg/show.do?processo.codigo $=$ CJ00001A6 0000\&processo.foro $=451>$. Acesso em: 19 nov. 2015.

SCHREIBER, Anderson. Direitos da personalidade. 2 ed. São Paulo: Atlas, 2013.

SILVA, Regina Beatriz Tavares da; SANTOS, Manoel J. Pereira dos (Coords.). Responsabilidade civil: responsabilidade civil na internet e nos demais meios de comunicação. 2 ed. São Paulo: Saraiva, 2012.

SOARES, Flaviana Rampazzo. Responsabilidade civil por dano existencial. Porto Alegre: Livraria do Advogado Editora, 2009.

TRENTIN, Taíse Rabelo Dutra; TRENTIN, Sandro Seixas. Internet: publicações ofensivas em redes sociais e o direito à indenização por danos morais. REDESG - Revista Direitos Emergentes na Sociedade Global, Santa Maria. v. 1, n. 1, jan.-jun. 2012, p. 83 e 84. Disponível em: <cascavel.cpd.ufsm.br/revistas/ojs2.2.2/index.php/REDESG/article/viewFile/6263/pdf>. Acesso em: 19 nov. 2015.

ZAGO, Gabriela da Silva. A possibilidade de responsabilização civil de terceiros por comentários na internet. Revista Anagrama: Revista Científica Interdisciplinar da Graduação, São Paulo, ano 4 - edição 1, set.-nov. 2010, p. 13. Disponível em: <www.usp.br/anagrama/Zago_ responsabilizacaocivil.pdf>. Acesso em: 19 nov. 2015.

Submetido em: Novembro de 2015.

Aprovado em: Março de 2016. 